\title{
A Study on the Status Quo of College Teachers' Professional Identity in Tianjin and Its Influencing Factors
}

\author{
Jiaxin Liu \\ Tianjin Maritime University, Tianjin 300350
}

\begin{abstract}
This paper mainly studies and analyzes the teaching work of teachers and summarizes factors influencing teachers' career according to the characteristics of teaching. It analyzes the status quo of college teachers' identification of their career in Tianjin under the social background of rapid development of information, including college teachers' identification of their career at present stage, explores factors affecting college teachers' identification of their careers from the features of schools as well as teachers' individual features. Besides, it analyzes and discusses factors affecting the overall level of teachers' identification of their career, and then proposes some relevant suggestions to improve college teachers' quality and ability as well as enhance colleges and universities' comprehensive strength according to the actual development of colleges and universities.
\end{abstract}

Keywords: College teachers; Professional identification; Improvement

\section{天津市高校教师职业认同现状及影响因素研究}

\author{
刘嘉欣 \\ 天津海运职业学院，天津市 300350
}

摘要: 本文主要研究分析教师的教育教学工作, 根据教学工作特点, 总结归纳教师职业的影响因素。通过分析在当前信息 化飞速发展的社会背景下天津市高校教师对自己的职业认同状况。其中包含高校教师现阶段的职业认同感, 以及探究从学校 特征和教师个体特征方面探究影响高校教师职业认同的影响因素, 并分析和讨论教师职业认同总体水平的影响因素。结合高 校的实际发展状况, 提出一些相关的建议, 提高高校教师的素质与能力, 增强高校的综合实力。

关键词: 高校教师; 职业认同; 提高

\section{1. 天津市高校教师职业认同现状}

根据数据显示, 与我国其他高校教师相比, 天津高校教师的职业认同感较高, 总体水平处于领先地 位。同时, 虽然许多教师希望在工作的同时实现个人价值, 但是其在职业价值观方面的认同值最低。这说 明不同的高校教师对其职业认同感有着明显差异。其实高等院校的等级一直是天津市高校教师现阶段的职 业认同感的重要组成部分, 不仅影响教师的总体水平, 而且影响学校外界的良好形象。一般来说, 重点高 校教师的素质与能力较高, 其职业认同总体水平处于领先地位, 明显高于普通院校, 同样, 普通院校的教 师的职业认同感则高于职业院校。另外, 对于高校而言, 一般根据教师的职业认同感来制定相关的薪资报 酬。同时, 学校制定的管理模式也与教师的素质与能力息息相关。当然, 学校周围环境等方面也不可忽略。 教师会随着其对学校管理模式、薪资报酬以及学校环境的满意度的增加而提升其职业认同感。另一方面, 高校教师的职称显著影响着天津市高校教师的职业认同感, 教师的职称越高, 教师对自身的职业认同感也 会随之提升。而教师从事教育教学工作的教龄, 对高校教师的职业认同感的影响不大。只是随着高校教师 教龄的增长, 其职业认同会呈现出替上升的趋势。理工类的高校教师的职业认同均高于文科类的教师的职 业认同水平。对天津市高校教师职业认同感的因素, 一方面与高校教师的素质与能力有关; 另一方面与高 
校的级别紧密联系在一起。同时, 还涉及教师在从事教育教学工作之前的培训进修经历、实习实训经验, 以及教师享受的各种优惠政策, 如科研基金等。当然, 高校学生的质量、具有的教学资源与数量、就业特 点等方面也不能忽略。因此, 要想提高高校教师的职业认同感, 不仅需要教师与高校之间的努力, 而且还 需要国家与社会的大力支持。

\section{2. 教师的个体特征影响着天津市高校教师的职业认同}

从整体水平上看，天津市高校教师的职业认同感并不存在年龄水平上的明显性差异，但是不能忽视的 是教龄与职业认同感会存在同等性增长的发展趋势。具体表现为教师的职业感情、职业意志、职业技能以 及相应的职业价值观念对教师职业认同的影响呈现正相关的关系, 即教师的年龄越大，对职业的感情就会 越深厚, 越热爱自己从事的职业, 越会在自己的教育家下工作中投入感情和精力, 对自己的职业认同就会 越高, 这也在一定程度上刺激了教师对自身职业的归属感以及教师对自身的专业技能提高的要求, 教师的 自身价值也会在以后的工作中体现出来，对于教育教学工作是十分有利的。教师的职业期望是随着年龄的 增加而逐渐降低的, 这说明相对于刚任职的教师来说, 年纪比较大的教师对自己的职业期望比较低, 工作 的积极性也会下降。40 岁以后这一年龄阶段的教师对职业技能水平的要求远远高于 40 岁之前的教师，这 是由教师经过多年的教学投入以及参与的技能培训所决定, 正是这种教龄的差异性, 产生了教师的教育教 学技能随着年龄逐渐提高。但是年纪如果较大的话, 接受新事物的能力也会减弱。天津市高校中的教师的 学历参差不齐, 这种学历之间的差异并没有对职业认同产生明显影响, 但是从教师的职业规划以及期望中 不难看出高学历的教师对自己的职业期望会高于相对较低学历的教师的职业期望。具体表现为博士学历的 教师相比其他学历教师具有更高的职业期望, 学士学位的教师职业期望为最低层次。因而从某种程度上来 讲, 更高的学历有利于教师对自我教学能力的提高。从另一方面也反应出高校对教师学历上的要求存在一 定的依据。但是博士学历对自己的职业认同也是相当不高, 这也是受到年龄和接受知识范围的影响。高校 教师应积极吸收新的知识和经验, 在这个告诉发展的信息时代, 抓住最为前沿的信息, 在最好的年纪里进 行学习。

教师职称对高校教师的职业认同存在极为显著的影响关系，一般而言，教授的职业认同感最为强烈， 具体表现在关于职业上的情感、意志、技能、期望和对职业的认知都普遍高于其他职称的教师。不过其中 令人难以置信的是教授的职业价值观认同是最低, 而教师助教的职业认同却是最高。这也是时代发展, 社 会对教师赋予了新的概念和要求，使得教师对自己的职业不再和以前那么认同，对自己的职业界定变得模 糊。高校教师的职业意志也是对着教师的教学年限的增加而提供的。教师职称对职业认同的影响的另一个 主要表现体现在教授的具有最高的职业意志, 这是其他助教、讲师等职称的教师难以相提并论的, 分析其 根本原因, 这与教授的教龄密不可分。而在教授之下自然是副教授, 同理而言其的教师职业认同感自然而 言是高于助教和讲师的职业认同。他们在工作中对自己的研究成果比较认同, 更积极投身到教育研究以及 教学工作当中。

天津市高校的教师职业认同度与年龄这一因素的关系表现为随着教师的教学年龄的增长呈现交替上 升的趋势。在影响职业认同的诸要素中, 教师的的职业认同水平是随着教师教书的年龄而提高的, 但是教 师的对于教师职业的期望却呈现一个下降的趋势。不过仍然不能忽视教龄对职业认同感的积极性影响, 从 某一方面来讲这是由于培训以及教学实践的累积促使了教师教学水平的增长, 这对提高教师专业技能认同 
有很大的作用。但是教师对自己的职业积极性在逐渐减弱, 即产生了职业倦急。这个时候学校就要给予教 师适当学习新知识的机会, 为老师的教学环境注入新的资源, 活跃教书氛围, 提高教师的积极性。在职业 意志和职业技能认同上，不同教龄的教师存在显著性差异，但是对于职业认同在教龄水平上不存在差异。 不同年龄阶段的教师在职业意志水平上存在着显著的差异，5-10 年和 20 年以上的教龄的教师拥有的职 业意志水平远远超过 5 年以下的教师, 结果显示是明显高于。教龄是 20 年的教师在职业技能认同上是最 高的, 显著高于其他教龄的教师。统计得出的最终结果, 即是教龄对高校教师的职业认同的影响规律一方 面与个体的情感发展特点密不可分, 另一方面这也与教师专业发展的规律相契合。教龄在 5 年以下的教师 多是刚从学校环境中毕业出来, 对教师的职业是满心的期待, 处于意志水平比较低的阶段, 对于教师的职 业认同也是停留在最初级的阶段, 也是教师生涯的适应期; 教龄在 5-10 年的教师是职业的发展诚实事情, 随着教龄的增加, 教师的意志水平正在增加, 正处于知识积累和经验总结的阶段, 教学热情比较高涨, 这 个时期已经基本形成了自己的教学体系，对职业也是充满了期待和满足; 教龄在 11-20 年的教师处于教师 生涯中的停滞期, 也是产生职业倦急的时期, 是教师离职比较严重的时期, 对教师职业认同比较低下; 最 后是教龄在 20 年以上的教师，处于这个教龄时期的教师一般会产生强烈的离职想法，工作的积极性和主 动性降低，很少有新的科研成果，对教师职业认同低。

从所教科目类别来看，文科类的高校教师职业认同要低于理工类，这是理工类学科性质所决定，但是 文科所具有的特点使得其在职业价值观方面却是优于理工类教师的职业价值观。一直流行一句话 “学好数 理化，走遍天下也不怕。”理工类教师的职业压力要高于文科类的高校教师，这导致在教师职业认同上理 工类教师具有较为显著的优势，并且还存在有理工类的教师的职业期望水平超过文科类高校教师这一现 象。

\section{3. 影响高校教师职业认同的因素}

教师对学校环境、学校的管理以及学校所给予的薪资水平的满意程度严重影响着教师的职业认同。教 师如果对学校工薪、环境以及管理的的满意度越高, 那么他们就会越喜欢从事这个学校的教育教学工作, 对自己的教学职业就会更多地投入时间和精力。学校工薪是教师生存的基本需要, 是老师生存的物质基础, 只有满足基本的物质需求之后, 只有满足于基本的物质需求之后, 老师才会更安心把更多的精力投入到教 学中去, 实现自身更高层次的价值。教师的职业意志能力也是受到教师工资的影响, 由于工资低, 许多地 区出现教师流动甚至是缺失的现象。在此基础上, 高校教师应该重视教师的基本需要, 完善学校对于教师 的管理系统, 从人性化程度出发, 密切关注教师的基本需要, 调动教师的积极性, 营造一个严谨但不失宽 松的管理模式, 师生关系融洽, 同事关系和谐的教学氛围, 只有这种优良的教学氛围才会促进教师在教学 教育工作中的创新性和创造性, 才会在工作中取得更好更高的成绩。

教师的一些个性特征。每个人都是独立的个体, 有着自己独特的人格特性, 对于教师来说也是不例外。 孔子早就提出要因材施教, 对于教师我们也要依据不同的人格特征来聘用。例如, 博士学历的教师对于职 业技能和社会期望就比其他学历的教师水平高, 教师的职称和职业意志水平严重影响着教师的职业认同, 一般来说, 教师的职称越高, 教师的职业认同越高, 高校可以给予教师一定学习考察的机会, 取得更高的 学历支持。 


\section{4. 对策}

影响教师职业认同的因素不是单一的, 而是多方面的, 主要有以下几点: 教师的职业期待、教师的学 历和职业素养、教师的社会地位、教师教学的环境 (包括学校环境、管理环境和文化氛围)、教师工资水 平、学校能够给与教师的可利用资源、学生素质以及社会对教师的认可程度和期望值, 除此之外教师的年 龄和教龄等因素都影响着教师的职业认同。

教师职业发展的内在动力室教师的职业认同，只有教师对自己的职业认同高了，教师对于自己的教育 教学工作才会更加积极主动, 更好的为自己的岗位服务, 发扬爱岗敬业、尽职尽责的优良传统美德。只有 教师对自己的职业认同高了, 才能有更多的创造性工作和实践能力, 更好的服务于学生和社会。这一点不 仅关系到教师自身的生理和心理成长, 对学生选择职业、增长知识以及促进学生健康成长于成才也是有重 要的作用和意义, 为社会创造出更多优秀人才。

高校是教师教育教学的主要平台, 如何提高教师的职业认同水平是高校现在要做的。一方面高校在管 理模式上要更加的人性化, 为教师创造一个良好的教育教学氛围, 包括师生之间和同事之间, 密切关注教 师的需求, 而不是追求教育数量忽略了教师的基本需要。另一个方面就是高校要针对不同教师的个性特征 给予教师关注, 不要一味的命令, 而要鼓励教师多做研究, 给予教师一定的学习深造的机会。此外, 为了 更有计划、更好的为学校教育教学服务, 高校教师必须结合自身的职业特点和专业特长制定相关学习计划、 职业规划和教学计划。积极参与学校组织的机修活动, 主动地和学校领导沟通对自身有利的发展对策。在 学校满足教师的基本需要的同事, 教师也要经常进行反思工作, 只有适时地反思才会促进教育教学工作。

“教师的反思” 对于教师开展教育教学工作十分重要。“五日三省吾身” 要时刻印在老师的脑海里, 美国著名心理学家提出一个教师成长的公式: 经验 + 反思=成长, 他是这样人为地, 经验是需要建立在反思 的基础上, 只有经过反思的经验才是充实的, 饱满的, 这种经验能够让教师在教学生涯中获得良好发展。 因此, 高校应该经常鼓励和指导教师反思工作, 教师也要形成反思的信念, 对自己已经形成的教师职业认 同和自身职业技能和专业经验要经常进行反思, 可以对以后的教育教学提供借鉴, 不断拓展自己的知识储 备, 有助于教师在以后的工作中更有创造性和积极性。不断地反思会提高教师的成就动机和职业成就感。

\section{References:}

[1] A Study on College Teachers' Professional Identity e [D]. Bo Yanling. Guangxin Normal University, 2008

[2] A Study on the Professional Identity of Teachers in Jiangxi Province since the New Century [D]. Yang Qing. Nanchang University, 2014

[3] Research on Teachers' Professional Identity in Newly - built Universities in Anhui Province [D]. Sha Rongxing. Anhui University, 2013

[4] A Study on the Professional Identity of English Teachers and Its Influencing Factors [D]. Yang Yanhua. Guangxi Normal University, 2011

[5] The Characteristics of Professional Identity of Intern Teachers [D]. Li Xuhong. Northeast Normal University, 2011

[6] Investigation and Research on Teachers' Professional Identity in an Independent Colleges [D]. Huang Dan. East China Jiaotong University, 2015 
[7] A Study on the Status Quo of University Teachers' Professional Identity [D]. Zhu Yan. Suzhou University, 2016

[8] A Study on the Relationship between Teacher 's Professional Identity and Learning Ability Self - efficacy in College [D]. Han Bing. Hebei Normal University, 2013

[9] A Microcosmic Study of Normal Teachers' Professional Identity [D]. Hao Xiaojuan. Yangzhou University, 2014

[10] A Study on the Relationship between Teachers' Professional Identity and Job Satisfaction and Job Burnout [D]. Liu Ling. Anhui University, 2014 